\title{
Surgical Results of Lumbar Canal Recalibration by Modified Senegas Technique
}

Norbery Jorge Rodríguez De La Paz ${ }^{1 *}$, Duniel Abreu Casas ${ }^{1}$, Mikail Da Conceição Sallé1, Orestes López Piloto ${ }^{1}$, Calixto Machado ${ }^{2}$, Brandon $^{1}$ Brock $^{3}$

${ }^{1}$ Institute of Neurology and Neurosurgery of Cuba, Department of Neurosurgery.

${ }^{2}$ Department of Clinical Neurophysiology of the Institute of Neurology and Neurosurgery, Havana, Cuba.

${ }^{3}$ Texas Woman's University, Department of Ph.D. Studies. Denton, TX, USA

*Corresponding Author: Norbery Jorge Rodríguez De La Paz, Institute of Neurology and Neurosurgery of Cuba, Department of Neurosurgery.

Received date: August 23, 2021; Accepted date: September 09, 2021; Published date: September 14, 2021

Citation: Norbery Jorge Rodríguez De La Paz, Duniel A. Casas., Conceição Sallé MD, Orestes L. Piloto., Calixto Machado, Brandon Brock. (2021) Surgical Results of Lumbar Canal Recalibration by Modified Senegas Technique. J. Neuroscience and Neurological Surgery. 9(4); DOI:10.31579/2578$8868 / 204$

Copyrights: (C) 2021 Norbery Jorge Rodríguez De La Paz. This is an open-access article distributed under the terms of The Creative Commons Attribution License, which permits unrestricted use, distribution, and reproduction in any medium, provided the original author and source are credited

\begin{abstract}
:
The aim of recalibration of the lumbar canal using the Senegas technique guarantees stability and preserves movement, with a considerable reduction in surgical risk and faster incorporation into daily life. Objective: To evaluate the surgical results of recalibration of the lumbar canal using the modified Senegas technique.

Materials and Methods: An ambispective and cross-sectional descriptive observational study was carried out at the Institute of Neurology and Neurosurgery between January 2011 and December 2019 that were evaluated 6 and 12 months after having been operated.

Results: $70.7 \%$ of the patients manifested chronic low back pain, and dysesthesia was found in $39.8 \%$. There were $15.8 \%$ complications. The clinical evolution according to the Lumbar and Lower Limb Verbal Numerical Scale and the functional one according to the Oswestry Disability Index was better at 6 and 12 months after the intervention compared to the preoperative period. The result was considered good at $82.7 \%$ and $89.4 \%$, respectively, at 6 and 12 months.

Conclusions: The clinical and functional evolution of the operated patients is significantly better at 6 and 12 months concerning the preoperative one. At both 6 and 12 months, surgical results are good in the vast majority of patients.

Keywords: lumbar canal stenosis; lumbar canal recalibration; modified senegas technique
\end{abstract}

\section{Introduction}

Currently, lumbar canal stenosis is a common cause of low back pain and lower extremity pain in older adults, with an incidence of 5/100000 and a prevalence of approximately 400,000 adults in the United States 23, it is the most frequent cause of spinal surgery in patients older than 65 years, with the improvement in life expectancy and the increase in the proportion of people over 65 years of age, the incidence of will increase even more proportionally, expecting $20 \%$ by 2026. [1] In Cuba, the prevalence of lumbar spinal canal stenosis is around $6 \%$ of the population. [2]

Since the spinal canals are the roots of the nerves and the spinal cord, when a narrowing of this canal occurs, the nerve roots can be compromised, originating characteristic symptomatology consisting of pain and sensory alterations radiating to the lower limbs.

Conservative treatment is based on the use of non-steroidal antiinflammatory drugs, physical therapy, which requires constancy and at least three months of continuity, and lifestyle changes, not always accepted by patients, and approximately $60 \%$ of cases do not resolve with that treatment. [3]

The most practiced surgical treatment until 5 or 6 years ago was decompression and posterior arthrodesis of the lumbar segment with or without instrumentation. Still, as it is not performed, immobilization in a cast brace is necessary for six months. A great limit that exists between conservative treatment and surgical, high risk. Hence, in 1988 Professor Jacques Senegas, in France, exposed his technique of systematic recalibration of the lumbar canal, by means of which the posterior arch, the articular facets, the disc, and the holes which are progressively dilated as necessary, causing minimal damage to the integrity mechanics and stability of the spine. Shortly after, he enunciated interspinous distraction as one more element of this recalibration. At the same time, he discussed a dynamic neutralization device (conservation of movement) that guarantees stability and preserves movement, significantly reducing surgical risk and faster incorporation into daily life. For this reason, the objective of the research is to evaluate the surgical results of recalibration of the lumbar canal using the 
modified Senegas technique. This modification proposed by us includes the endoscopic support approach as an essential tool to avoid damage to the neurovascular structures, improving the surgical field's vision. In this case, the ligamentoplasty is optional. [4]

\section{Materials and Methods}

An descriptive observational study was carried out in patients who underwent recalibration of the lumbar canal by the Senegas technique modified in the INN between January 2011 and December 2019.

The universe consisted of all the patients operated on for lumbar canal stenosis. The sample was non-probabilistic and consisted of 133 patients operated on for lumbar canal stenosis using the modified Senegas technique with the information source the clinical histories of the patients treated in the INN.

The inclusion criteria were: patients over 19 years of age, of either sex, with lumbar canal stenosis demonstrated by imaging tests (CT and/or MRI), the condition between L1-S1, the persistence of symptoms after conservative treatment for a minimum of six months, or in the presence of progressive neurological deficit.

The exclusion criteria were: patients with tumor or pseudotumoral pathology associated with the affected level, patients who underwent surgery at the level of the lumbar spine, spondylolisthesis greater than $25 \%$ slip, lateral listhesis greater than $4 \mathrm{~mm}$, non-degenerative causes of stenosis, lateral curves greater than $20^{\circ}$ associated with a degenerative process (associated scoliosis $>20^{\circ}$ ), psychiatric diseases that do not allow the functional evaluation to be carried out.

The variables studied were: age, sex, time of evolution, affected level, symptoms, signs, intraoperative complications, postoperative complications, Lumbar Verbal Numerical Scale (VNS), VNS lower limbs, Index of Oswestry Disability (ODI) and Surgical Outcomes.

The source of information was the patient's medical history. The clinical information was collected in collection charts and were included in a data collection worksheet.

The variables under study were expressed according to their respective summary measures as the arithmetic mean, standard deviation, median, interquartile range, minimum and maximum for the quantitative ones, and numbers and percentage for the qualitative ones.

To identify the association of the quantitative variables, the JI test of independence and the correlation coefficients (Pearson, Spearman), were used. For qualitative variables, t-test test was used to compare means and medians.

\section{Final evaluation}

The patients were evaluated 6 and 12 months after being operated on. The measurement of both lumbar and lower limb pain was performed using the Verbal Numerical Scale (VNS) and functional assessment using the Oswestry Disability Index (ODI).

To estimate the results of surgery at 6 and 12 months, the Macnab classification was used, which considered the result as:

- Good: when there was no presence or only occasional presence (mild-moderate) of lumbar or radicular pain, the patient was able to carry out their usual task or work, there was no or minimal restriction to perform physical activities and could walk more than 2 kilometers without pain

- Regular: When the patient reported mild persistent or occasional moderate lumbar and / or radicular pain, he was able to work with some restriction but was able to perform most of the normal activities.

- Bad: when the patient referred occasional persistent and / or severe moderate lumbar and / or radicular pain with little or no relief after surgery, persistence of radicular symptoms, was unable to work, had severe restrictions in daily activity and was not able to walk less of 500 meters without pain.

\section{Ethical considerations}

The study was carried out according to the Declaration of Helsinki, modification of Fortaleza, Brazil, on research on human beings. For this, authorization was requested from the Neurosurgery service to access the clinical records, and the database of the patients included in the study, with the responsibility and obligation not to disclose the information collected, keeping it strictly confidential

\section{RESULTS}

The age of the patients ranged between 35 and 78 years, with a mean of 66.32 \pm 8.98 years and a predominance of cases between 60 and 69 years with 52 $(39.1 \%)$. A total of $84(63.1 \%)$ patients were male. $67.7 \%(n=90)$ of the cases had more than 12 months of disease evolution, with a median of 21.80 \pm 6.11 months, minimum of 5 and 43 months maximum. The most affected levels were L4-L5 in $47.4 \%(\mathrm{n}=63)$, L5-S1 in 30.1\% $(\mathrm{n}=40)$ and L3-L4 in $15.8 \%(\mathrm{n}=21)$.

The symptoms referred by the patients were chronic low back, radicular pain continuous or intermittent and neurogenic claudication, dysesthesia, hypoesthesia, hyporeflexia and motor deficit. (Table 1).

\begin{tabular}{|c|c|c|c|}
\hline \multirow{2}{*}{$\mathbf{N}$} & Frequency & $\mathbf{\%}$ \\
\cline { 3 - 4 } & $\mathbf{1 3 3}$ & $\mathbf{1 0 0}$ \\
\hline \multirow{4}{*}{ Symptoms* } & Chronic low back pain & 94 & 70.7 \\
\cline { 2 - 4 } & Root pain & & \\
& • Intermittent & 33 & 24.8 \\
& - Continuous & 46 & 34.6 \\
\hline \multirow{4}{*}{ Signs * } & Neurogenic claudication & 69 & 51.9 \\
\cline { 2 - 4 } & Motor deficit & 31 & 23.3 \\
\cline { 2 - 4 } & Hypoesthesia & 40 & 30.1 \\
\cline { 2 - 4 } & Dysesthesia & 53 & 39.8 \\
\cline { 2 - 4 } & Hyporeflexia & 35 & 26.3 \\
\hline
\end{tabular}

* The same patient had more than one symptom/sign. 


\section{Table 1: Clinical manifestations.}

There were a total of 21 complications (Table 2), that was presented intraoperatively and consisted of injury to the dura mater, the remaining ones occurred postoperatively and surgical wound infections, chronic pain, and epidural fibrosis and reoperation, respectively.

\begin{tabular}{|l|l|l|l|}
\hline \multirow{2}{*}{$\mathbf{N}$} & Frequency & $\%$ \\
\cline { 3 - 4 } \multirow{2}{*}{$\begin{array}{l}\text { Intraoperative } \\
\text { complications }\end{array}$} & Bleeding & $\mathbf{1 3 3}$ & $\mathbf{1 0 0}$ \\
\cline { 2 - 4 } & Incidental durotomy & - & - \\
\hline \multirow{4}{*}{ Postoperative complications } & Surgical wound infection & 8 & 3.0 \\
\cline { 2 - 4 } & Chronic pain & 5 & 6.0 \\
\cline { 2 - 4 } & Epidural fibrosis & 2 & 3.8 \\
\cline { 2 - 4 } & Motor and / or sensory deficit & - & - \\
\cline { 2 - 4 } & Residual compression & - & - \\
\cline { 2 - 4 } & Reintervention & 2 & 1.5 \\
\hline
\end{tabular}

Table 2: Intra and postoperative complications.

Regarding the clinical and functional evolution of the patients studied (Table 3);

\begin{tabular}{|c|c|c|c|c|}
\hline $\mathbf{N}$ & Evaluated moment & Mean \pm SD & $\begin{array}{l}\text { Difference } \\
\text { Pre / Post }\end{array}$ & T-Test \\
\hline \multirow{3}{*}{ Lumbar ENV } & Preoperative & $5.26 \pm 1.50$ & & \multirow{3}{*}{$\mathrm{p}=0.000$} \\
\hline & 6 months & $3.56 \pm 2.04$ & $1.70 \pm 1.86$ & \\
\hline & 12 months & $2.80 \pm 1.78$ & $2.46 \pm 1.71$ & \\
\hline \multirow{3}{*}{$\begin{array}{l}\text { ENV lower } \\
\text { limbs }\end{array}$} & Preoperative & $8.38 \pm 0.78$ & - & \multirow[b]{3}{*}{$\mathrm{p}=0.000$} \\
\hline & 6 months & $1.92 \pm 2.57$ & $6.46 \pm 2.56$ & \\
\hline & 12 months & $1.56 \pm 2.35$ & $6.82 \pm 2.36$ & \\
\hline \multirow[b]{3}{*}{ ODI } & Preoperative & $\begin{array}{l}65.23 \\
13.72\end{array}$ & - & \multirow[b]{3}{*}{$\mathrm{p}=0.000$} \\
\hline & 6 months & $\begin{array}{l}30.34 \quad \pm \\
22.29\end{array}$ & $\begin{array}{l}34.89 \\
25.93 \\
\end{array}$ & \\
\hline & 12 months & $\begin{array}{l}28.38 \\
21.33\end{array}$ & $\begin{array}{l}36.85 \\
23.27\end{array}$ & \\
\hline
\end{tabular}

Table 3: Clinical and functional evolution.

Surgical results, at six months postoperatively, were good in $110(82.7 \%)$, fair in $19(14.3 \%)$ and poor in 4 (3.0\%), and at 12 months, they were good in 119 (89.4\%), fair in $14(10.6 \%)$ and foul in none, significant results have been statistically analyzed (Table 4$)$.

\begin{tabular}{|c|c|c|c|c|c|c|}
\hline \multirow[b]{3}{*}{$\mathbf{N}$} & & \multicolumn{2}{|l|}{6 months } & \multicolumn{2}{|l|}{12 months } & \multirow{3}{*}{ Test $\mathrm{X}^{2}$} \\
\hline & & Frequency & $\%$ & Frequency & $\%$ & \\
\hline & & 133 & 100 & 133 & 100 & \\
\hline \multirow{3}{*}{$\begin{array}{l}\text { Surgical } \\
\text { results }\end{array}$} & Good & 110 & 82.7 & 119 & 89.4 & \multirow[b]{3}{*}{$\mathrm{p}=0.004$} \\
\hline & Regular & 19 & 14.3 & 14 & 10.6 & \\
\hline & $\mathrm{Bad}$ & 4 & 3.0 & 0 & 0 & \\
\hline
\end{tabular}

Table 4: Surgical results.

\section{DISCUSSION}

There is a worldwide consensus that spinal canal stenosis occurs mainly between the fifth and sixth decades of life, [5] these results are consistent with those of this and other investigations [6,7] and they are explained because as people age the ligaments of the spine thicken and harden (a process called calcification), bones and joints are deformed forming osteophytes and hernias or disc protrusions commonly appear, in addition to spondylolisthesis, all factors that lead to lumbar canal stenosis. [8] 
As observed in this and other studies, most lumbar canal stenoses begin with a segment, with L4-L5, followed by L5-S1, being the most affected because they are the ones that receive the most significant load and due to the accumulation of microtraumas, which favors the development of degenerative processes. As the disease becomes progressive, it secondarily affects other, generally higher segments, becoming multisegmental, and although some patients present the method in several segments from the onset of the disease, this is not the rule. [9]

The clinical presentation of lumbar canal stenosis is generally given by chronic low back pain, radiculopathy, and intermittent non-vascular claudication. The clinical symptoms in the patients included in this series are similar to those published in the literature. Lower limb pain is present in approximately 70 to $80 \%$ of patients, while low back pain is present in $60 \%$ to $65 \%$. [10] This also has mechanical characteristics, long evolution and is accompanied by poorly defined and sometimes changing neurological symptoms in the lower extremities. Although the clinical examination of the lumbar spine usually provides little data, motor deficits that are not observed with the patient at rest can be found frequently, as well as symmetrical reduction of reflexes and some loss of sensation. Complications derived from decompression surgery for lumbar canal stenosis range between 15-30\% according to the literature, [11] being the most frequent, incidental durotomy, $(3.1 \%-13 \%)$, postoperative neurological deficit $(5 \%)$, infection $(0.5 \%)$ and vascular lesions (less than 0.02\%). [12]

In the study of Tabares Neyra, [13] only minor complications occurred, 90 of the 102 patients did not suffer perioperative complication for a high $88.2 \%$, the highest incidence was the lesion of the dura mater with four cases. In three patients, there was superficial wound infection, resolved by antibiotic therapy and local cure. Two patients suffered a neurological injury, and one had difficulty urinating. They recovered with the administration of steroids and vitamin therapy. Two patients were classified as other complications due to postanesthetic confusional state, from which they recovered in a short time. No complications related to non-fusion occurred in patients treated with instrumentation. Also, in the Cuban context, Mauri Pérez et al. [14] report $13 \%$ complications associated with the lumbar canal stenosis recalibration technique, of which $5 \%$ were dura mater lesions, $3 \%$ neurological deterioration, $2 \%$ deep infections, $2 \%$ venous thrombosis, and $1 \%$ death. Likewise, Försth et al. [15] report dural injury as complications in 12 patients $(11 \%)$ in the group where decompression plus vertebral fusion was performed (group 1) and in $13(11 \%)$ in the decompression alone group (group 2).

Recalibration of the lumbar canal using the Senegas technique is based on performing decompression of each vertebral segment where the stenosis occurs, respecting the stability of the segment and the part of the posterior bone arch, and resecting the upper half of the bone, inferior lamina, the yellow ligament, and the medial half of the facets [4] With the application of this modified technique without interspinous ligamentoplasty.

By endoscopic approach, a statistically significant improvement $(\mathrm{p}<0.05)$ was obtained, both in functional status (the mean decrease in ODI concerning the preoperative period) and the assessment of lumbar pain and lower limbs (mean decrease in lumbar and lower limb VNS compared to the preoperative period) in the revisions carried out at 6 months and one year after surgery. This is consistent with previous article published in the literature, although it should be noted that no work was found using this surgical technique. In a study conducted by Luque et al. [6] where patients with lumbar canal stenosis underwent minimally invasive tubular decompression (unilateral approach and bilateral decompression), the preoperative median of the ODI was 29 (interquantile range 24-35), which decreased to 7 (interquantile range 5-9). The preoperative median of the VAS was 7 (interquantile range 7-8), observing in the last control, carried out at 6 months, a decrease to 2 (interquantile range 1-2). Using Senegas instrumentation and recalibration technique from Santos Coto et al. [16], a marked improvement in pain symptoms was observed in the postoperative period in patients with neurogenic claudication. Using an Oswestry index, scores decreased from 62.7 to 22.1. As for patients with low back pain, the average Oswestry index from 77.1 decreased to 15.7. The visual analog scale behaved as follows, in patients with neurogenic claudication, which was on average between 67 decreased to 3 ; in the cases of lumbociatalgia, it decreased from 8-9 to 2 . Likewise, the patients with lumbar canal stenosis included in the Taleb series [17] They were treated by recalibration of Senegas, and the postoperative evaluation was carried out using the Lassale score.

On the other hand, Çavusoglu et al. [18] obtained a statistically significant decrease in ODI by performing a bilateral decompression using a unilateral laminectomy (group 1) and unilateral laminotomy (group 2) (preoperative mean value of group I was $31.14 \pm 9.27$, with the final mean value of 14.02 \pm 9.27 at $4-7$ years, and in group II, the preoperative mean value of $29.62 \pm$ 8.19 , to $12.4 \pm 6.3$ in group 2) [mean followup 5.4 years, range 4-7 years]. In the series by Danta Matos et al [19] patients with lumbar canal stenosis underwent a decompression technique. In the preoperative period, the VAS values for low back pain ranged between 0 and 9 (mean $4.2 \pm 3.37$ ), while in the postoperative period they ranged between 0 and 2 (mean $0.85 \pm 0.88$ ) on the first day, between 0 and 5 (mean of $1.05 \pm 1.19$ ) per week and between 0 and 4 (mean of $1.15 \pm 1.04$ ) per month, statistically significant results. Likewise, the preoperative VAS values for lower limb pain ranged between 0 and 9 (mean $8 \pm 1.72$ ). In contrast, postoperatively they ranged between 0 and 4 (mean $0.7 \pm 1.13$ ) on the first day, between 0 and 3 (mean of $0.85 \pm$ 1.04 ) per week, and between 0 and 3 (mean $1.05 \pm 1$ ) per month, statistically significant results. In the work of Cano Rodríguez and González Moga [20] the recalibration of a single root (group A) with that of multiple roots of a segment (group B) in patients with lumbar canal stenosis. In group A, there was a decrease of 46.63 points on the Oswestry scale, which improved pain by $66.73 \%$. In group B, on the other hand, an average reduction of 34.54 points on the Oswestry scale, equivalent to $47.23 \%$.

Regarding the lumbar canal recalibration procedures, the good results vary in the literature reviewed between 82 and $91 \%$, a range within which the results obtained in this study are found and which agree with those reported by other researchers such as Andrasinova et al [21], Otani et al., [22] Ha et al. [23]] and Akbary et al. [24]

\section{Study limitations}

The main limitation of the present study is its ambispective design, which means that when data are collected from medical records, there may be errors in their interpretation.

\section{CONCLUSIONS}

Our study shows that the complications derived from this technique are within the range described in the literature for patients who receive decompression of the lumbar canal, with a significantly better clinical and functional evolution of the operated patients at 6 and 12 months concerning the preoperative. Both at 6 and 12 months, the surgical results were rated as good in most patients.

\section{REFERENCES}

1. Ai Min W, Fei Z, Yong C, Dong Dong X, Wei H, Bin Z, et al. Lumbar spinal steosis: an update on the epidemiology, diagnosis and treatment. AME Med J 2017; 2:63. doi: 10.21037 / amj.2017.64.13. 
2. National Statistics Office, CEPDE. Life expectancy. Cuba and provinces. 2005-2007. Calulation by sex and ages. Havana: ONE. [Internet] 2008 [cited April 2020].

3. Muñiz Luna L, Camargo Zetina C, Vilchis Sámano H, Ibarra Stone KA, Silva Chiang E. Factors associated with persistence of pain in lumbar stenosis surgery. Coluna / Columna 2018; 17 (2): 110-116. doi.org/10.1590/S1808185120181702190993.

4. Senegas J. Revue de chirurgie orthopedique et reparatrice de Í appereil moteur. J Orthop Surg 1988; 2: 93-99.

5. Zylbersztejn S, de Freitas Spinelli L, Rodinei Rodríguez N, Mariotti Werlang P, Kisaki Y, Roberto Mieres Ríos A, et al. Degenerative stenosis of the lumbar spine. Rev Bras Ortop 2011; 47 (3): 286-91. doi: 10.1590 / S010236162012000300002.

6. Alvarenga G, Araújo Rotini JO, Asano LYJ, Alves de Andrade V, Marcondes Cesar AE, Valesin Filho ES, et al. Lumbar spinal stenosis: evaluation of pain and life quality after surgical treatment. Coluna / Columna 2019; 18 (1): $37-$ 42. di.org/10.1590/S1808-185120191801168174

7. Luque LL, Sainz A, Seclen D, Marchetti, Erice S, Lambre J. Minimally invasive decompression for lumbar canal stenosis: technique and early clinical results. Rev Argent Neuroc [Internet]. 2018 [cited April 2020]; 32 (2): 134-145.

8. Johnsson KE, Rosen I, Uden A. The natural course of lumbar spinal stenosis. Clin Orthop 1992; 279: 82-86.

9. Arbit E, Pannullo S. Lumbar stenosis. A clinical review. Clin Orthop 2001; 138: 137-143.

10. Parai $\mathrm{C}$, Hägg $\mathrm{O}$, Lind $\mathrm{B}$, Brisby $\mathrm{H}$. The value of patient global assessment in lumbar spine surgery: an evaluation based on more than 90,000 patients. Eur Spine J 2018; 27: 554-63. doi.org/10.1007/s00586-017-5331-0.

11. Machado GC, Maher CG, Ferreira PH, et al. Trends, Complications, and costs for hospital admission and surgery for lumbar spinal stenosis. Spine (Phila Pa1976) 2017; 42: 1737-1743.

12. Kamson S, Trescot AM, Sampson PD, Zhang Y. Fullendoscopic assisted lumbar decompressive surgery performed in an outpatient, ambulatory facility: Report of 5 years of complications and risk factors. Pain Physician 2017; 20 (2):

13. Tabares Neyra H. Degenerative lumbar stenosis: a new therapeutic / surgical approach in the elderly. [Doctor of Medical Sciences thesis online]. University of Medical Sciences of Havana. Havana Cuba. 2013.

14. Mauri Pérez O, Candebat Candebat R, Echevarría Resqueijo H, Candebat Rubio R, Louit Hechavarria A, Sosa Carrasco
M. Recalibration of the lumbar canal in stenosis. Manual of medical practices [Internet]. 2011 [cited April 2020].

15. Försth P, Ólafsson G, Carlsson T, Fröst A, Borgström F, Fritzell $\mathrm{P}$, et al. A randomized, controlled trial of fusion surgery for lumbar spinal stenosis. N Engl J Med 2016; 374 : 1413-1423.

16. Santos Coto C, Rivas Hernández R, Fleites Marrero E. Surgical treatment of lumbar canal stenosis. Rev Cubana Ortop Traumatol [Internet]. 2009 [cited April 2020]; 23 (2).

17. Taleb C. Post-surgical evaluation of degenerative lumbar stenosis surgery by selective decompression method. Coluna / Columna [Internet]. 2006 [cited April 2020]; 5 (1): 13-18.

18. Çavusoglu H, Kaya RA, Türkmenoglu ON, Tuncer C, Çolak I. Aydın Y. Midterm outcome after unilateral approach for bilateral decompression of lumbar spinal stenosis: 5-year prospective study. Eur Spine J 2007; 16: 2133-2142.

19. Dantas Matos T, Osorio García Y, Tavares Costa HR, Aparecido Defino HL. Preliminary results of vertebral canal decompression by spinous process splitting. Coluna / Columna [Internet]. 2019 [cited April 2020]; 18 (3): 231235.

20. Cano Rodríguez AI, González Moga A. Clinical evolution of decompressive surgery in the treatment of degenerative narrow lumbar canal. Acta Ortopédica Mexicana [Internet]. 2016 [cited April 2020]; 30 (4): 185-190.

21. Andrasinova T, Adamova B, Buskova J, Kerkovsky M, Jarkovsky J, Bednarik J. Is there a correlation between degree of radiologic lumbar spinal stenosis and its clinical manifestation? Clin Spine Surg 2018; 31 (8): 1. doi: 10.1097 / BSD.0000000000000681.

22. Otani K, Kikuchi SI, Nikaido T, Konno SI. Magnitude of dural tube compression does not show a predictive value for symptomatic lumbar spinal stenosis for 1year follow-up: a prospective cohort study in the community. Clin Interv Aging. 2018; 13: 1739-46. doi: 10.2147 / CIA.S171049.

23. Ha S, Hong Y, Lee S. Minimally invasive lumbar spinal decompression in elderly patients with magnetic resonance imaging morphological analysis. Asian Spine J 2018; 12 (2): 285-93. doi: 10.4184 / asj.2018.12.2.285.

24. Akbary K, Kim JS, Park CW, Jun SG, Hwang JH. Biportal endoscopic decompression of exiting and traversing nerve roots through a single interlaminar window using a contralateral approach: technical feasibilities and morphometric changes of the lumbar canal and foramen. World Neurosurg. 2018; 117: 153-61. PMID: 298557220. 


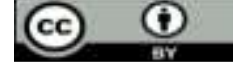

This work is licensed under Creative Commons Attribution 4.0 License

\section{To Submit Your Article Click Here: Submit Manuscript}

DOI: $10.31579 / 2578-8868 / 204$
Ready to submit your research? Choose Auctores and benefit from:

* fast, convenient online submission

* rigorous peer review by experienced research in your field

* rapid publication on acceptance

* authors retain copyrights

* unique DOI for all articles

* immediate, unrestricted online access

At Auctores, research is always in progress.

Learn more https://auctoresonline.org/journals/neuroscience-andneurological-surgery 